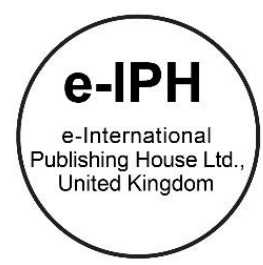

\title{
Improving Community Behaviour Towards Sustainable Mobility for Liveable Neighbourhoods
}

\author{
Nurain Mohd Talmizi, Halmi Zainol, Suharto Teriman, Nor Eeda Ali \\ Faculty of Architecture, Planning and Surveying, Universiti Teknologi MARA, \\ Seri Iskandar Campus, Seri Iskandar, 32610, Perak, Malaysia \\ nuraintalmizi@gmail.com \\ Tel: 60194113224
}

\begin{abstract}
Major challenges of sustainable environment are identifying the community and predicting the behaviour of each community in neighbourhoods. Many local authorities are eager to overcome these issues to improve their sustainability. The research focuses on the behaviour of community in neighbourhoods. The study is conducted with 135 samples. The main factors that contribute in successful relationship between the community behaviour factors towards sustainable mobility. Cronbach's Alpha coefficient level showed all the factors exceeding 0.80 and all dimensions have a good reliability value. A contributing factor of community behaviour has been discovered to reduce the negative effects of congestion, crime and vandalism.
\end{abstract}

Keywords: Community behaviour; sustainable mobility; neighbourhood

eISSN: 2398-4287@ 2017. The Authors. Published for AMER ABRA by e-International Publishing House, Ltd., UK. This is an open access article under the CC BYNCND license (http://creativecommons.org/licenses/by-nc-nd/4.0/). Peer-review under responsibility of AMER (Association of Malaysian Environment-Behaviour Researchers), ABRA (Association of Behavioural Researchers on Asians) and CE-Bs (Centre for Environment-Behaviour Studies), Faculty of Architecture, Planning \& Surveying, Universiti Teknologi MARA, Malaysia.

https://doi.org/10.21834/e-bpj.v2i6.994

\subsection{Introduction}

The cycle of decline illustrates how poor quality housing, badly maintained local environments, problems with antisocial behaviour, crime and disorder including drug and alcohol misuse can cause instability in residential neighbourhoods. The behaviour of people involved in various activities is a major factor affecting the environment and nature protection. This study aims to evaluate the influencing community factors towards neighbourhood sustainable mobility. In this study, the objective is to examine the community contributing factors of behaviour towards sustainable mobility.

In this study, sustainable mobility refers to the time and costs required for travel. Mobility is higher when average travel times, variations in travel times, and travel costs are low. According to Fattah, Badarulzaman, \& Ali, (2015) neighbourhood involves the social and physical viewpoints under substantive and worldly points of view for current conditions and future changes. The term neighbourhood is a very significant concept in the study of residential mobility behaviour of individuals and households. Most studies of neighbourhoods and community initiatives geared toward neighbourhood improvement and make simplifying assumptions about boundaries. Most studies rely on census geography or political jurisdictions to operationalise the neighbourhood units. According to Goetz and Edward (2010), a good neighbourhood is less dependent on social services and has decent economic self-sufficiency, in which the residents enjoy safety and neighbourhood satisfaction, good employment in a stress-free environment.

\subsection{Literature Review}

Neighbourhoods usually have some particular physical or social characteristics that distinguish them from the rest of the settlements.

eISSN: 2398-4287C 2017. The Authors. Published for AMER ABRA by e-International Publishing House, Ltd., UK. This is an open access article under the CC BYNCND license (http://creativecommons.org/licenses/by-nc-nd/4.0/). Peer-review under responsibility of AMER (Association of Malaysian Environment-Behaviour Researchers), ABRA (Association of Behavioural Researchers on Asians) and cE-Bs (Centre for Environment-Behaviour Studies), Faculty of Architecture, Planning \& Surveying, Universiti Teknologi MARA, Malaysia.

https://doi.org/10.21834/e-bpj.v2i6.994 
Eriksson (2008) defines behaviour as more altruistic individuals who are more likely to express a behaviour for example to reduce car usage; whereas, ego-oriented individuals express no concern over significant consequences. A behavioural intention refers to a person's subjective probability that they will perform some form of behaviour.

According to Nasrudin, Rostam, and Rose (2014), the majority of population is aware of the impact of motor vehicles on the environment, and agree that motor vehicles are a major contributor to environmental issues. Therefore, various strategies have been taken to establish to reduce car ownership such as neighbourhoods without cars or reduced use of cars as well as community bicycle programmes. Therefore, this study focuses on behaviour among community in residential neighbourhood in Section 7, Shah Alam, Selangor. One of the factors influencing community is their behaviour towards sustainable mobility (Scheiner \& Holz-Rau, 2013) in residential neighbourhood (De Sa \& Ardern, 2014; Liu \& Liddawi, 2015). Furthermore, sustainable residential neighbourhood can be achieved through reduction of private car usage and increasing the use of non-motorised from of transportation. The level of behaviour will have effect on policy making and strategies of the government (Hasmi et al., 2015).

People might want to walk, cycle, or take other forms of outdoor exercise near their homes, but they fear they would be injured as a result of violent attacks. It has been claimed that people who live in neighbourhoods that are unsafe face particular difficulties. This study has identified literature gaps of behaviour (Pattanayak \& Pfaff, 2009; De Sa \& Ardern, 2014) to improving sustainable mobility in residential neighbourhood. In this study, perhaps it is due to the attitudes which affect their choice of using private cars even though they think they can walk.

Neighbourhood mobility behaviour is a complex entity that has a relationship with the various aspects of a person's physical environment and behaviour (Robert, Broman, \& Basile, 2013). It is important to integrate the nuances of neighbourhood mobility behaviour, into planning processes, which aim to influence the demand side of transport as a way of understanding towards utilization of non-motorized by Garling \& Friman (2012).

\subsection{Methodology}

This study adopts a quantitative approach, using survey questionnaire as an instrument for data collection to evaluate 15 community behaviour items. The questionnaire surveys were conducted primarily on face to face basis with respondents to enhance understanding and to assist respondents on specific terminology elaboration. A stratified random sampling were employed to select potential respondents, who are head of household residing in section 7, Shah Alam. The survey involved sampled households living in various accommodation types of housing namely low cost housing (45 respondents), medium cost housing (45 respondents) and high cost housing (45 respondents) which amounted to 135 respondents. Responses from these sampled respondents were obtained through the face to face survey.

All items in the questionnaire were measured using Likert Scale that comprised of five answer choices from (1) strongly disagree to (5) strongly agree. The validation for factors towards sustainable mobility in residential neighbourhood was done by conducting a factor analysis using Statistical Package for the Social Science (SPSS) software. Factor analysis only explores an item and suggests a factor for each of the items. The Cronbach's Alpha value was used to determine the level of reliability through the internal consistency for each factor.

In case of secondary data and general conditions of areas these were compiled using document search. The sampling technique has been described followed by the measurement procedures. This paper started by highlighting the demographic of respondents sampled in the study. It went further to describe various stages employed in the data cleaning and screening and how the measure of reliability was arrived at before the factor analysis was conducted.

\subsection{Analysis and Findings}

This section consists of behaviour in residential neighbourhood. The behaviour factors in this study have been divided into five elements namely neighbourhood security, neighbourhood street connectivity (walkability), neighbourhood infrastructure, neighbourhood destinations and neighbourhood aesthetics. These dimensions were measured by the following of 19 variables: neighbourhood safety, neighbourhood crime, Safe walkability and cycling routes, Safety area, Pleasant walkability, Pedestrian linkages, Broken sidewalk, Zebra crossing, Pedestrian routes, Health and Wellbeing, Walking view, Splendor and pleasant, Walking distance, Transit stop, Different routes, Dangerous at night, Fast moving traffic, Crossing streets, and new lighting. The results of the factor analysis showed that thirteen items loaded cleanly into four factors explaining a total of $60.23 \%$ of the variance. All the items had factor loadings greater than 0.50. Again, applying Pallant (2010) rule which states that items with communalities $<0.50$ should be deleted, six items (transit stop, different routes, dangerous at night, fast moving traffic, crossing streets, and new lighting were deleted from the analysis because their communalities were $<0.50$. The Kaiser-Mayer-Olkin value for the items was 0.64 and the Bartlett's Test of Sphericity was significant.

The level of reliability was determined through the internal consistency for each factor that was determined by calculating the Cronbach's Alpha value. Cronbach's Alpha coefficient level showed all the factors exceeding 0.80 . These results explain all items construct have good internal consistency, indicating that all dimensions have a good reliability value. This study found that the neighbourhood security achieved a good reliability value (0.73) and the neighbourhood infrastructure achieved a moderate value (0.56). Meanwhile, the neighbourhood aesthetic has an Alpha value of less than 0.40 , the result of which is related to the number of item which was poor and inadequate to measure the construct (Tavakol, 2011). This is because the Cronbach's Aplha value was sensitive towards the number of items used whereby if the number of items was small in the scale used, the Cronbach's Alpha value 
must therefore be small (Pallant, 2010). Likewise, neighbourhood walkability obtained a negative Alpha value (-152) indicating that it has in consistency reliability issue.

Table 1 shows the results of for items of the first factor (neighbourhood security). The mean score (in order of magnitude) of these items are: neighbourhood safety (3.07) and standard deviation (STD) of 1.05, neighbourhood crime (Mean=3.04, STD=0.97), safe walkability and cycling routes (Mean=2.96, STD=0.92), and safety area (2.74) and STD of 0.96 . Neighbourhood safety recorded highest in terms of factor loading shows that traffic has a very strong influence on neighbourhood security. In other words, the level traffic experienced in the neighbourhoods in study area has great consequence on security. Safety of walking and cycling routes in the neighbourhood equally affects the respondents perception of security. Nobody, would want to engage in cycling or walking when the security in the neighbourhood is not guaranteed.

Table 1. Neighbourhood security

\begin{tabular}{lcrrrr}
\hline & $\mathrm{N}$ & Minimum & Maximum & Mean & $\begin{array}{c}\text { Std. } \\
\text { Deviation }\end{array}$ \\
\hline Factor 1: Neighbourhood security & & & & & \\
Neighbourhood safety & 135 & 1 & 5 & 3.07 & 1.05 \\
Neighbourhood crime & 135 & 1 & 5 & 3.04 & 0.97 \\
Safe Walking and cycling routes & 135 & 1 & 5 & 2.96 & 0.92 \\
Safety area & 135 & 1 & 5 & 2.74 & 0.96 \\
\hline
\end{tabular}

The results in Table 2 shows the second factor, which is neighbourhood walkability, with three items loaded in order of their magnitude (mean score). These are: pleasant walkability (3.98) and STD of 0.63 , pedestrian linkages (Mean=3.69, STD=0.85), and broken sidewalk (Mean=2.62, STD=0.91). Pleasant walkability, as could be seen from the results recorded the highest mean score. This is not surprising because people in judging whether a neighbourhood is walkable or not, attach great premium on pleasant walking lanes or routes. Equally, pedestrian linkages also play a major role as people term those neighbourhoods with easy and accessible links as being walkable. However, this factor was dropped from further analysis because the internal consistency of reliability is negative $(-152)$.

Table 2. Neighbourhood walkability

\begin{tabular}{lrrrrr}
\hline & N & Minimum & Maximum & Mean & $\begin{array}{c}\text { Std. } \\
\text { Deviation }\end{array}$ \\
\hline Factor 4: Neighbourhood walkability & & & & & \\
Pleasant walkability & 135 & 1 & 5 & 3.98 & 0.63 \\
Pedestrian linkages & 135 & 1 & 5 & 3.69 & 0.85 \\
Broken sidewalk & 135 & 1 & 5 & 2.62 & 0.91 \\
\hline \multicolumn{2}{c}{ (Source: Author, 2016) }
\end{tabular}

Table 3 shows the third factor of behaviour, that is neighbourhood infrastructure. It has three items loaded in order of their magnitude (mean score): zebra crossing (3.84) and STD of 0.68 , pedestrian routes (3.73) and STD of 0.69 , health and wellbeing (3.67) and STD of 1.02. Zebra crossing as could be seen from the results recorded the highest mean score among the items. What this suggests therefore, is that respondents attached greater importance to zebra crossing among the neighbourhood infrastructure. Providing zebra crossing infrastructure in a neighbourhood would encourage walking as people feel safe.

Table 3. Neighbourhood infrastructure

\begin{tabular}{lcrrrr}
\hline & $\mathrm{N}$ & Minimum & Maximum & Mean & $\begin{array}{c}\text { Std. } \\
\text { Deviation }\end{array}$ \\
\hline Factor 3: Neighbourhood infrastructure & 135 & 1 & 5 & 3.84 & 0.68 \\
Zebra crossing & 135 & 1 & 5 & 3.73 & 0.69 \\
Pedestrian routes & 135 & 1 & 5 & 3.67 & 1.02 \\
Health and wellbeing & (Source: Author, 2016) & &
\end{tabular}

For the last factor of behaviour which is neighbourhood aesthetic, the results in Table 4 shows that it has three items. The items in order of their magnitude (mean score) are walking view (4.01) and STD of 0.54, splendor and pleasant (2.93) and STD of 0.90 and walking distance (3.98) and STD of 0.51. Walking view recorded the highest mean score among the items measuring neighbourhood aesthetic. This implies that respondents perceive walking view as a major component of neighbourhood aesthetic.

Table 4. Neighbourhood aesthetic

\begin{tabular}{lccccc}
\hline & N & Minimum & Maximum & Mean & $\begin{array}{c}\text { Std. } \\
\text { Deviation }\end{array}$ \\
\hline $\begin{array}{l}\text { Factor 4: Neighbourhood aesthetic } \\
\text { Walking view }\end{array}$ & 135 & 1 & 5 & 4.01 & 0.54
\end{tabular}




\begin{tabular}{lccccc} 
Splendor and pleasant & 135 & 1 & 5 & 2.93 & 0.90 \\
Walking distance & 135 & 1 & 5 & 3.98 & 0.51 \\
\hline & (Source: Author, 2016)
\end{tabular}

The result of the data analysis seems to have provided basis for the justification of the research objectives. Leaning upon existing theory of Planned Behaviour, a confirmatory factor analysis was conducted to identify the various factors that influence behaviour of residents in the study area towards adopting sustainable mobility. It was found from the factor analysis that behaviour has four factors. According the factors analysis of behaviour, factor one is neighbourhood security with four items. The four items are neighbourhood crime (0.83), neighbourhood traffic (0.82), walkability and cycling routes (0.67), and safety area (0.57). Factor 2 which is neighbourhood walkability has three variables. The variables are: pleasant walking $(0.79)$, pedestrian linkages $(0.71)$, and broken sidewalk (-503). The third factor 3 is neighbourhood infrastructure. It has three variables namely: safe crossing (0.74), pedestrian routes $(0.74)$, and health and wellbeing (0.65). The last factor (4) which is neighbourhood aesthetic has three variables walking view (0.83), splendor and pleasant (-0.62), and walking distance $(0.55)$.

According to the survey results for behaviour of community, this measure varies between 0 and 1 , and values closer to 1 are better. A value of 0.60 is a suggested minimum (Sekaran \& Bougie, 2009). Kaiser-Meyer Olkin measure of sampling adequacy suggested that the sample was factorable $(\mathrm{KMO}=0.64)$. The alpha coefficient for the ten items is 0.63 , suggesting that the items have relatively high internal consistency (Hamid et al., 2011; Sekaran \& Bougie, 2009; Henseler, Ringle \& Sinkovics, 2009; Creswell, 2008; Fornell \& Larcker, 1981). From 19 to 13 items (Deleted six items because below communalities 0.50, (Pallant, 2010) such as transit stop, different routes, dangerous at night, fast moving traffic, crossing streets, new lighting. Factor analysis was conducted on 13 items using the Principal Component Analysis. The factor analysis was repeated with a Kaiser-Meyer-Olkin value of 0.64 The first factor recorded the highest variance explained of 20.83 , followed by second factor (19.22), third factor (11.14) and fourth (9.04). The highest variance explained obtained for the first shows that it has the largest contribution to the changes in total variance of the items. The highest of four factors accounted for 60.23 .

According to Hasmi et al., (2015), behaviour factors will help the movement towards sustainable mobility of community behaviour. The study could be replicated in another section in Shah Alam before applying it to an urban area. Behaviour of movement of mobility in neighbourhood will affect movement of mobility in urban area (Basile et al., 2011).

\subsection{Discussion}

The behaviour of individuals towards public transport and non-motorized modes are important to know as they have major effect on modal shares. Furthermore, being pro-transit, pro-walking, and pro-cycling means not only enhancing the service quality if these options. Besides, removing the many built-in subsides and incentives that promote auto-mobility. The behaviour of residential in neighbourhood area makes the difference between developing and developed countries.

From past literature, a conceptual framework for this study was developed. The scale measures three factors of behaviour of community towards sustainable mobility: neighbourhood security, neighbourhood infrastructure and neighbourhood aesthetic. The reason for choosing behaviour of community towards sustainable mobility is based on (Prillwitz \& Barr, 2009) who opined that behaviour play a very important role in sustainable mobility. This study aimed to evaluate the influencing community factors towards neighbourhood sustainable mobility see Figure 1.

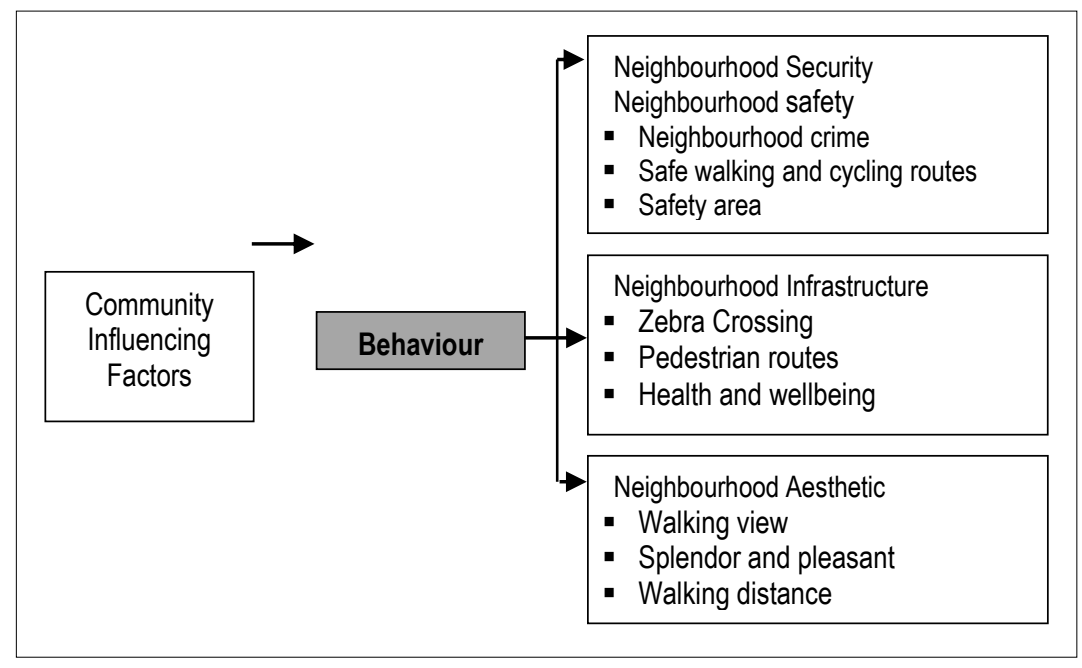

Fig. 1: The influencing factors of behaviour towards sustainable mobility

This study will aid in identifying of those factors that influence behaviour towards sustainable mobility. The study identified three factors for behaviour: neighbourhood security, neighbourhood infrastructure and neighbourhood aesthetic. Neighbourhood walkability 
factor was dropped because of the negative result due to small sample sizes and small numbers of items. The elements in residential neighbourhood may be an important factor in achieving sustainable mobility. Thus, it may be essential to target policy instruments that incorporate some of the factors identified in this study.

The results of this study supports the findings of an earlier study conducted on behaviour (Avineri et al., 2010; De Sa \& Ardern, 2014) that influence the community towards sustainable mobility. Previous studies (Ali, Zani, \& Kasim, 2014; Garling \& Friman, 2012; Samuelsson, 2013) showed that these dimensions are important to sustainable mobility in residential neighbourhood. The neighbourhood quality factors, which is similar as the quality of life approach, by examining the residents' perceptions and cognition towards three major indicators of physical, social and economic attributes. Most people are concerned and have varying levels of satisfaction about their housing and neighbourhood surroundings.

This paper strongly suggests that the health benefits of walking or cycling vastly outweigh the risk of being hit by a motor vehicle. If safety of walking and cycling is given due priority in transport planning. This study builds on previous studies in several ways. First, when it comes to changing environments to encourage physical activity, the most promising strategies with the perceived desirability of environments for walking and cycling, and prioritizing the characteristics that both children and adults view as attractive. The negative effects of the environment as a result of the use of vehicles, and need to be given knowledge especially in community factors of changing behaviour of each person. Using a factor analytical method, this study has been able to identify those factors that influence the behaviour of residents in Section 7 of Shah Alam city, towards adopting sustainable mobility such as cycling and walking. Findings from the factor analysis show that four influence behaviour towards sustainable mobility. The findings lend support to earlier works on Theory of Planned Behaviour (Supavititpatana et al., 2012). The findings of this study suggest that policy makers and local authority need to measure these factors towards sustainable mobility, because these factors and items impact every policy making and strategies of the government (Coulton, Theodos, \& Turner, 2012).

\subsection{Conclusion and Recommendations}

In conclusion, there are various predictors of neighbourhood quality and quality of life consisting of the physical, social and economic attributes. On-going and future research would further expand on the neighbourhood quality strands. Walking and cycling have many potential benefits, both for our communities and for us as individuals. To realise these benefits, people must have safe and convenient choices to change their current pattern of travel. Achieving this requires attention to the way we plan our transport systems for active modes and how accessible we can make our communities. Results from the literature review underline the necessity to distinguish between different forms of travel with regard to distance and frequency of trips. In the field of daily travel, a variety of sociopsychological variables are the main determinants for decisions pro- and contra-sustainable behaviour. There, the habitual character of daily mobility is seen to be a major barrier for changes towards a more sustainable behaviour. Findings for environmentally related individual behaviour at home strengthen the role of socio-psychological factors as drivers for behavioural decisions and focal points for measures targeting behavioural change.

The results show that socio-demographic factors had significant relationship to community factors towards sustainable mobility in residential neighbourhood. However, it should be stressed that environmental concern was a significant impact factor on willingness to participate in reduce individual mobility in the future. Furthermore, socio-demographic factors were related to the behaviour towards sustainable mobility related to less interest in cars and less subjective norm of car ownership. Positive experience as car passenger had the highest positive relationship to intentions to commute by car in the future, in addition to high subjective norm. Low intentions were related to high willingness to accept limitations of car travel in the future and low perceived behavioural control. Positive cycling experience was also the strongest mediating factor for strong intentions to cycle in the future, as were negative attitudes to the car, high willingness and bicycle friendly future vision. Subjective norm of car ownership was negatively associated to bicycle intentions.

Furthermore, regarding the quality, condition, maintenance, and improvement of facilities in the study area, it would be important to conduct a study that focuses the role of local authorities with respect to management and maintenance. For the findings of this paper showed that four factors of behaviour towards sustainable mobility were extracted through the factor analysis. The first variables which is neighbourhood security has four variables namely; neighbourhood safety, neighbourhood crime, safe walkability and cycling routes, and safety area. While the second factor is neighbourhood infrastructure has three items namely; zebra crossing, pedestrian routes, and health and wellbeing. The third factor is neighbourhood aesthetic has three items namely; walking view, splendor and pleasant, and walking distance. The percentage of total variance was $60.23 \%$ and the result of the Kaiser-Meyer-Olkin value was 0.64 , which was higher than the recommended value of 0.60 . Thus, the study concluded that a positive (direct) relationship between the community influencing factors of behaviour towards sustainable mobility. Based on the findings, it is obvious that behaviour of residents towards sustainable mobility is tied to security, infrastructure and aesthetic. The element in residential neighbourhood may be an important factor in achieving sustainable mobility. Thus, it may be essential to target policy instruments that incorporate some of the factors identified in this study.

Conducting a study on a subject matter like this which involves perception of how people feel is quite revealing. According to the result obtained from the study, three factors influence behaviour towards sustainable mobility in residential neighbourhood. These factors have been identified as important for sustainable mobility at Section 7, Shah Alam. The factors are: Neighbourhood Street Connectivity, Neighbourhood Safety of Crime, Neighbourhood Safety of Traffic, Neighbourhood Security, Neighbourhood Infrastructure and Neighbourhood Aesthetic. It is hoped that local authority should incorporate these factors of behaviour when examining the factors that influence sustainable mobility in the study area. Furthermore, this study is helpful in comparing the Malaysian experience with the western literature and also applying the concept of accessible distance to community facilities. The 
neighbourhood quality factors, which is similar as the quality of life approach, by examining the resident's perceptions and cognition towards three major indicators of physical, social and economic attributes. Perceptions of safety influence whether people view walking and cycling positively or negatively. Walking and cycling are not inherently dangerous, nor are pedestrians and cyclists usually a danger to each other. Most risk is as a result of walking and cycling on transport networks that are designed for motor vehicles, combined with the speed and volumes of the motor vehicles themselves.

Congestion also leads to community health impacts because it increases air pollution, noise, and indirectly causing stress and health implications. Furthermore, most people prefer to use their car over other modes of transport to commute every day, which is closely related to human psychology. There is need to come up with strategies that would improve the appeal of places to attract people. For example, at night time, lighting to avoid dark places of concealment and to plan places that foster physical activity. Communities should compare the findings from physical and perceptual measures with knowledge of how these characteristics affect visual appeal and physical activity, for example walking. In conclusion, the study strongly suggests that the health benefits of walking or cycling vastly outweigh the risk of being hit by a motor vehicle. If safety of walking and cycling is given due priority in transport planning, there is no good reason not to promote these modes. This study builds on previous studies in several ways. First, when it comes to changing environments to encourage physical activity, the most promising strategies with the perceived desirability of environments for walking and cycling, and prioritizing the characteristics that both children and adults view as attractive. The negative effects of the environment as a result of the use of vehicles, and the need to identify those community factors that bring about change in behaviour towards sustainable mobility. Finally, conducting research in another neighbourhood section would help reveals the community factors towards sustainable mobility.

\subsection{Acknowledgements}

This research was supported by Universti Teknologi MARA, Seri Iskandar, Perak and Higher Education of Ministry.

\subsection{References}

Ali, S., Zani, R., \& Kasim, K. (2014). Intention - behaviour relations : A conceptual and literature review. Research Journal of Finance and Accounting, 5(19), $168-178$.

Avineri, E., Chatterjee, K., Darnton, A., Goodwin, P., Lyons, G., Musselwhite, C.,Wiltshire, P. (2010). Individual Behaviour Change : Evidence in transport and public health.

Basile, G., Broman, G., \& Robert, K. H. (2011). A systemsbased approach to sustainable enterprise: requirements, utility and limits in S. McNall, J. Hershauer, and G. Basile, editors. The business of sustainability, 1. Praeger Press, New York, USA.

Coulton, C., Theodos, B., \& Turner, M. A. (2012). Residential Mobility and Neighborhood Change: Real Neighborhoods Under the Microscope. Cityscape, 14(3), 55-89.

Creswell, J. W. (2008). Educational research: Planning, conducting, and evaluating quantitative and qualitative research. Upper Saddle River. NJ: Merrill.

De Sa, E., \& Ardern, C. I. (2014). Neighbourhood walkability, leisure-time and transport-related physical activity in a mixed urban-rural area. PeerJ, 2, e440.

Eriksson, L. (2008). Pro-environmental travel behavior : and transport policy measures.

Fattah, H. A., Badarulzaman, N., \& Ali, K. (2015). Advances in Environmental Biology Factors Affecting Neighbourhood Quality: A Conceptual Framework. Advances in Environmental Biology Adv. Environ. Biol, 9(94), 26-30.

Fornell, C., Larcker, D.F., (1981). Evaluating structural equation models with unobservable variables and measurement error. Journal of Marketing Research. 18(1), 3950 .

Garling, T., \& Friman, M. (2012). A Behavioural Perspective on Voluntary Reduction of Private Car Use. Keep Moving, Towards Sustainable Mobility.

Goetz, E. G. (2010). Better Neighborhoods , Better Outcomes ? Explaining Relocation Outcomes in HOPE VI, 12(1), 5-32.

Hamid, M. R. A., Mustafa, Z., Idris, F., Abdullah, M., Suradi, N. R. M., Sains, F., Matematik, S. (2011). Measuring Value - Based Productivity : A Confirmatory Factor Analytic ( CFA ) Approach. International Journal of Business and Social Science, 2(6), 85-93.

Hasmi, M., Abdul, H. N., Leong, T. P., Masria, M., \& Rohana, S. (2015). Towards predicting the walkability of pedestrian rail commuters in Kuala Lumpur conurbation. 2nd International Conference on "Global Trends in Academic Research," 2, 280-298.

Henseler, J., Ringle C. M., \& Sinkovics, R. R. (2009). The use of partial least squares path modeling in international marketing. Adv. Int. Market., $20,277-319$.

Liu, Q., \& Liddawi, S. (2015). Key Factors of Public Attitude towards Sustainable Transport Policies : A Case Study in Four Cities in Sweden.

Nasrudin, N., Rostam, K., \& Rose, R. A. C. (2014). Persepsi penduduk Shah Alam terhadap dasar pengangkutan dan kesediaan mengguna pengangkutan mampan Transportation policies and the readiness of local public for sustainable transportation - A perception study of Shah Alam , Malaysia. Malaysian Journal of Society and Space, 2(2), 133-142.

Pallant, J. (2010). A Step by Step Guide to Data Analysis Using the SPSS Program - SPSS Survival Manual 4th Edition (4th ed.). London: Mc Graw Hill Education. 
Pattanayak, S. K., \& Pfaff, A. (2009). Behavior, Environment, and Health in Developing Countries: Evaluation and Valuation. Annual Review of Resource Economics, 1(1), 183-217.

Prillwitz, J., \& Barr, S. (2009). Motivations and Barriers to Adopting Sustainable Travel Behaviour, 1-12.

Robèrt, K. H., Broman, G. I., \& Basile, G. (2013). Analyzing the concept of planetary boundaries from a strategic sustainability perspective: How does humanity avoid tipping the planet? Ecology and Society, 18(2).

Samuelsson, A. (2013). Automobility , car-normativity and sustainable movement ( s ), (95), 135-142.

Scheiner, J., \& Holz-Rau, C. (2013). Changes in travel mode use after residential relocation: A contribution to mobility biographies. Transportation, 40(2), 431-458.

Sekaran, U., \& Bougie, R. (2009). Research Methods for Business: A Skill Building Approach, 5th edition, John Wiley \& Sons Ltd., United Kingdom.

Supavititpatana, B., Phancharoenworakul, K., Yeo, S. A., \& Sinsuksai, N. (2012). Using Theory of Planned Behavior to predict physical activity intention among pregnant Thais. Pacific Rim International Journal of Nursing Research, 16(3), 192-205.

Tavakol, M., \& Dennick, R. (2011). Making sense of Cronbach's alpha. International journal of Medical Education, 2, 53-55. 